\title{
Nacional-liberalismo: la legitimación del franquismo entre capitalismo tardío y guerra fría
}

\section{National-Liberalism: the Legitimation of Francoism between Late Capitalism and the Cold War}

\author{
Juan Carlos Sales ${ }^{1}$ \\ Universitat Jaume I (España) \\ ORCID: https://orcid.org/0000-0002-0984-271X
}

Recibido: 12-11-2020

Aceptado: 28-05-2021

\section{Resumen}

Desde al menos 1945, el régimen de Franco condicionó su existencia a la capacidad de adaptarse a las exigencias del mundo occidental de posguerra, en diversos aspectos políticos y sociales. Los cambios más visibles en el seno del franquismo fueron tanto la progresiva desaparición de elementos puramente fascistas como la asunción de un rol católico y anticomunista que hiciera más afable la cara del Régimen, lo cual se correspondió con un acercamiento al reciente aliado estadounidense. Sin embargo, estas transformaciones deben verse en un contexto más amplio, englobando una perspectiva historiográfica que les otorgue pleno sentido. La tesis que se defiende aquí es que la línea económico-política que siguió el franquismo, especialmente a partir de los años 50 (planificación, desarrollismo, modernización...), estuvo legitimada y auspiciada por un discurso concreto - y hegemónico en la parte Occidental de Europa- que tiene como base una visión de la historia asimismo única o hegemónica: la historia del liberalismo económico de guerra fría, así como la idea de modernización que se deriva de ella.

Palabras-clave: ordoliberalismo, modernización, franquismo, historiografía.

${ }^{1}$ (jusales@uji.es). Este artículo se enmarca dentro del programa de Formación del Profesorado Universitario, con referencia FPU16/04193, desarrollado en el grupo de investigación Historia Social Comparada de la Universitat Jaume I. 


\begin{abstract}
Since at least 1945, the Franco regime conditioned its existence on the ability to adapt to the demands of the postwar Western world, in various political and social aspects. The most visible changes in the Franco regime were both the progressive disappearance of purely fascist elements and the assumption of a Catholic and anti-communist role that made the face of the Regime more affable, which corresponded to a rapprochement with the recent American ally. However, these transformations must be seen in a broader context, encompassing a historiographic perspective that gives them full meaning. The thesis defended here is that the economic-political line that Francoism followed, especially from the 50s (planning, developmentalism, modernization ...) was legitimized by a concrete discourse -hegemonic in the Western part of Europe- which is based on an hegemonic vision: the history of cold war economic liberalism, as well as the idea of modernization that derives from it.
\end{abstract}

Keywords: Ordoliberalism, Modernization, Francoism, Historiography.

\title{
1. Introducción: historiografía y legitimación
}

La conocida teoría sobre el "fin de la historia", típica todavía en algunos sectores neoliberales conservadores y clásica ya desde Francis Fukuyama, representa ajustadamente -más allá de su solvencia teórica- una concepción historicista ligada al liberalismo que se basa en la simplificación política auspiciada por el contexto de los años 90 del siglo XX. Como se sabe, su tesis pretende diluir los contrapesos del comunismo y el socialismo para sostener que la única vía exitosa para el mundo desarrollado, que acabará por implantarse tarde o temprano en todos los Estados en proceso de modernización, es la democracia liberal burguesa y el capitalismo de mercado (Fukuyama 1992).

Por el lado estrictamente académico, siquiera plantear que la historia ha llegado a su fin entra de lleno en la querella de la historiografía misma por razones suficientemente obvias. De pronto se plantean implícitos puntos cardinales del oficio del (meta)historiador, como la conceptualización de la mayúscula Historia como un proceso unidireccional, o como el desarrollo de realidades inaprensibles que llegan a un fin final. Poner sobre la mesa este tipo de escorzos teóricos, amparados en una concepción histórica decimonónica

\footnotetext{
${ }^{2}$ El artículo en el que se basa (The end of history?) fue publicado en el verano de 1989 en la revista The National Interest, y traducido al español para la revista Claves en abril de 1990. Tras la caída del mundo soviético, Fukuyama amplió su contenido hasta convertirlo en libro, despojándole además de los interrogantes. La mencionada respuesta en History Today fue publicada como libro (After the End of History), traducido para la revista valenciana Debats con el título "A propósito del fin de la historia" (1992).
} 
teleológicamente indefendible para las posteriores etapas, no significa sino negar, al mismo tiempo, todas aquellas vetas de pensamiento autónomo y crítico que renovaron la forma de entender la historia en el siglo $\mathrm{XX}$, como bien demuestra la multiplicidad de escuelas, enfoques y metodologías que desarrollaron la ciencia histórica hasta como la conocemos actualmente.

De este modo, no es baladí que el principal eco académico en respuesta a las tesis de Fukuyama proviniera precisamente de la revista de divulgación History Today, en un monográfico que recogía diversas contribuciones de académicos estadounidenses y europeos, y que el principal foco de interés no fuera tanto la crítica al modelo económico e ideológico que postulaba como único, sino defender las teorías marxistas de la historia como contenedoras de amplio valor crítico e historiográfico. Ellos mismos habían podido diferenciar entre la validez de un discurso historiográfico concreto y unos postulados políticoideológicos que en realidad no tenían un vínculo necesario e irreductible: "El mayor peso de la argumentación ofrecida por Fukuyama estriba simplemente en la afirmación de que el marxismo -el leninismo, en realidad- está muerto como guía para la construcción política del antiguo bloque soviético" (Ryan et al. 1994: 11).

A este respecto, Fukuyama defendió que su "final de la Historia" no significaba la ausencia de hechos y nuevos retos, ni tampoco que el liberalismo se impondría de forma fáctica en todos los territorios del globo. El asentamiento del mercado y la democracia solo tendrían opción de darse, realmente, una vez se llevara a cabo la modernización de los países altamente industrializados. Este segundo punto es de suma importancia, porque nos devuelve a la discusión clásica en torno al tópico de que la modernización de un Estado - en sentido amplio- conlleva el germen de la unidireccionalidad histórica señalada.

Esta visión sobre la evolución de los Estados y las sociedades ha sido también ampliamente discutida $\mathrm{y}$, si bien es más reciente de lo que pareciera, actualmente se puede considerar rebatida. Josep Fontana escribió un opúsculo al albur de toda esta efervescencia historiográfica, propia de finales de siglo, en el que identificó la visión unívoca de la historia correlativamente a la conciencia burguesa industrializadora (Fontana 1992: 132 y ss.). De ahí provendría, ateniéndonos a esa explicación, la equivalencia entre el proceso industrializador portador de la mejora económica y tecnológica con el concepto -tan primario precisamente para la burguesía decimonónica- de progreso.

Para el ámbito académico contemporáneo, sin embargo, parece claro que la industrialización no conlleva de suyo las premisas de la democratización. En general, la mejora económica resultado de la implementación de medidas técnicas o de la eficacia administrativa que sustenta este tipo de procesos no precipitan ni democratización ni liberalismo, si bien pueden ser agentes modernizadores en un mero sentido "burgués" o, a lo sumo, condicionantes 
positivos que impulsen la emancipación social bajo ciertas circunstancias. Solo así se podría entender la anomalía que representa, entre otros muchos casos históricamente conocidos, la España de Franco: un Estado desarrollado, según las mediciones de agencias independientes de la época, con un proceso industrializador rápido y un crecimiento económico prácticamente inigualable ${ }^{3}$.

Pero si todo esto es cierto, si la modernización no concluye en democratización, ni siquiera en un tibio liberalismo político, ¿de dónde procede la supuesta legitimidad internacional del franquismo para esta época? Más allá de su mera supervivencia por factores de política externa, ¿cómo pudo el franquismo legitimar su sistema político, entrando en el relato histórico de la Europa desarrollista y comunitaria?

\section{El contexto de Guerra Fría. Hegemonía repartida}

El mundo se volvió bipolar poco después de 1945. Este es el diagnóstico usual de los manuales de historia que reconstruyen la segunda mitad del siglo $\mathrm{XX}$, y que además implica una ulterior diferenciación que pivota en torno a los años 70: una primera parte de reconstrucción europea y creación de alianzas de diferente signo -la Golden Age de Hobsbawm- y una segunda parte que comenzaría con la crisis que truncó la tendencia positiva en la economía Occidental y terminaría con la caída del régimen soviético (Judt, 2012; Hobsbawm, 1994). Aun con estas distinciones, lo que caracteriza de forma nítida y continua esta mitad de siglo sigue siendo la rivalidad de las dos superpotencias que lucharían hasta el final por imponer su propia línea ideológica al resto del mundo.

Durante la posguerra, la imposición de la ideología liberal/capitalista de raigambre estadounidense llegó por vías muy concretas. Más allá del conocido Plan de Recuperación, que fue la aportación material más importante hacia la paulatina americanización de Europa, se encontraban toda una serie de recientes apariciones institucionales y acuerdos que estaban destinados a hacer germinar todo un sistema nuevo de relaciones interestatales (Judt 2012: 358): Consejo de Europa, Comunidad Europea del Carbón y del Acero, Unión Europea de Pagos, Organización del Tratado del Atlántico Norte... El objetivo de estos tratados, pactos e inyecciones de capital era, principalmente, la estabilización política y económica de la Europa arrasada tras la guerra, así como la consolidación de unas clases medias que evadiese la posibilidad de que el comunismo pudiera penetrar entre la miseria y el desánimo social. A este respecto, no hay que olvidar

\footnotetext{
3 Este diagnóstico es, claro está, el relativo a la economía de la última parte del franquismo, especialmente la que comprende la etapa de 1960. Ver: F. J. Paniagua, La ordenación del capitalismo avanzado en España 1957-1963 (Barcelona, 1977), J. Nadal (comp.), La economía española en el siglo XX. Una perspectiva histórica (Barcelona, 1994).
} 
que desde la instauración de la influencia norteamericana se asumen también sus discursos, y no solo en cuanto a las pautas de consumo, sino también a la cultura popular. Por tanto, la fundamentación del nuevo orden mundial -ya no solo económico, sino ideológico, social y cultural- desde la visión liberal del Estado americanizado debía imponerse como la única posibilidad real, adelantándose a las mismas pretensiones que configuraban el imperialismo de la Unión Soviética (Núñez Seixas 2015: 65 y ss.).

Para el entonces presidente del Partido Socialdemócrata de Alemania Kurt Schumacher, un comentador excepcional de la época, el objetivo de este proceso era crear una Europa capitalista y, a la vez, clerical y conservadora (Judt 2006: 395). Precisamente estas características del nuevo sistema Occidental eran, en alguna medida que en seguida concretaremos, compartidas por el franquismo. A eso tuvo que agarrarse la España de los años de posguerra para no acompañar a sus homólogos fascistas en la desaparición ${ }^{4}$. Ahora bien, ¿qué es lo que llegó a España de esta americanización? Pues no se encontraba al principio en ninguno de esos nuevos organismos europeos, y tampoco recibió ayuda del Plan Marshall, si bien se le designaron otras líneas de crédito con similar propósito. Desde luego que no llegó el estadio de la normalización parlamentaria ni de la apertura social hacia los derechos civiles. En España desembarcó, por el momento, otro de los parámetros que estaban dentro de las agendas liberales: la difusión de técnicas de gestión política y económica de inspiración capitalista (Núñez Seixas 2015: 11). De ello se hablará en el siguiente apartado. Lo que no hay que dejar de resaltar ahora es el decisivo paso del franquismo desde su existencia desagradable y problemática a la posición de prevalencia internacional en virtud de su condición de "dictador amigo". Las armas con las que contaba, en la situación bipolar de guerra fría (anticomunismo, catolicismo, posición geoestratégica...), lograron que el Régimen se viera como un defensor más $-\mathrm{y}$, por cierto, bastante valioso- de la civilización Occidental de naturaleza ya descrita. Veamos brevemente cómo España puso el primer pie en el escenario que caminaba hacia el "final de la historia".

Para empezar, el franquismo se fue ajustando progresivamente a los estándares de una economía que se imponía ideológicamente en contra del enemigo socialista. Para las etapas de planificación desarrollista copiaron directamente las directrices francesas que se habían estado practicando desde el Plan Monnet (Nadal 1994:18). El marco económico se fue liberalizando y, finalmente, España consiguió entrar en algunos respetados organismos dedicados al desarrollo de los países democráticos occidentales. No son

\footnotetext{
${ }^{4}$ Conocida es la expresión del omnipresente almirante Carrero Blanco: "No tenemos más que tres [armas], pero serán eficaces si se las maneja con habilidad: nuestro catolicismo, nuestro anticomunismo y nuestra posición geográfica". J. Tusell, Carrero. La eminencia gris del régimen de Franco (Madrid, 1993), p. 117.
}

Araucaria. Revista Iberoamericana de Filosofia, Política, Humanidades y Relaciones Internacionales, año $23, \mathrm{n}^{\circ} 47$. Segundo cuatrimestre de 2021. Pp. 233-253. ISSN 1575-6823 e-ISSN 2340-2199 https://dx.doi.org/10.12795/araucaria.2021.i47.11 
desconocidas, por otro lado, las ausencias de transformaciones que, fuera del ámbito estrictamente económico, repercutieran en el carácter político-social, con lo que el franquismo siguió siendo, pese a las novedades, lo que era desde el principio: una dictadura tradicionalista y ultracatólica. Si hubo intentonas de "cambios" reales dentro del sistema político franquista estas no fueron más que insustanciales lavados de imagen jurídicos de cara al exterior, como muestra sintomáticamente la aprobación de un irrisorio constitucionalismo en base al Fuero de los Españoles, de 1945.

Como se ha apuntado anteriormente, la industrialización y el desarrollo económico de un país no implica por sí mismo la adopción de unas políticas sociales acordes a ese desarrollo, por el simple hecho de que ambos fenómenos son autónomos e irreductibles el uno al otro. Este es el argumento de quienes defienden que una economía desarrollada no tiene porqué ser consecuencia de una política democrática o liberal, por lo que se pone en duda la idea de la modernización como único camino a la prosperidad social ${ }^{5}$. Todo ello encuentra su ejemplo en la relación que mantuvieron España y Estados Unidos ya por los años 40. Como se sabe, desde los primeros contactos entre la oficialidad del franquismo y los representantes políticos del Congreso estadounidense, hubo tensiones por la necesidad de España de obtener ciertos beneficios (desde económicos e industriales a institucionales y militares) y el requisito de los norteamericanos de que el franquismo fuera implementando medidas rumbo a la normalización democrática.

Ante la reticencia de los actores políticos del franquismo a implementar medidas democráticas que de alguna forma pusieran en peligro, aunque fuera mínimamente, los pilares rígidos del Régimen, y viendo cómo el bloque soviético crecía hasta convertirse en una gigante amenaza real, a Estados Unidos no le quedó otra opción que entablar la relación diplomática con un aliado que a la postre sería descrito como de dictador amigo: "Una vez que quedó en claro para el gobierno de Madrid que el precio de la ayuda al régimen prestase la potencia líder en el mundo occidental no iba a consistir de ningún modo en exigencias de cambio político democratizador, el horizonte se vio despejado: cualquier otro precio podía pagarse... y se pagó" (Viñas 1981: 28-29).

\section{Formas de legitimación: burocratización y catolicismo político}

Pere Ysàs y Carme Molinero (2008) hablan con gran criterio acerca de la naturaleza del régimen de Franco en el contexto de posguerra antes detallado.

\footnotetext{
${ }^{5}$ Como veremos en el siguiente apartado, la "modernización" como tal puede tener diferentes rostros, y para hablar de un caso como el franquismo, donde sí se modernizaron ciertas estructuras, hay que acotar bien las parcelas donde estos procesos tienen lugar.
}

Araucaria. Revista Iberoamericana de Filosofia, Política, Humanidades y Relaciones Internacionales, año $23, \mathrm{n}^{\circ} 47$. Segundo cuatrimestre de 2021. Pp. 233-253. ISSN 1575-6823 e-ISSN 2340-2199 https://dx.doi.org/10.12795/araucaria.2021.i47.11 
Su diagnóstico reside en detectar la imposibilidad de integración en el nuevo mundo "aliado", debido a su incapacidad de evolucionar hacia formas que recompusieran su esencial legitimidad ganada en la Guerra Civil. El sentido de "legitimidad", en este caso, queda cercado por una conceptualización del franquismo como la imposibilidad de su existencia. Por así decir, su mera existencia contradeciría los nuevos fundamentos europeos, al menos virtualmente. Aun admitiendo ciertos éxitos basados en lo económico que le permitieron alargar la supervivencia, su irremediable disolución unida como un destino trágico a la desaparición de su cabeza suprema (Franco) evidencia, para estos autores, una falta de legitimación real en el estatuto del franquismo. El problemático proceso interno de institucionalización en sus distintos aspectos ofrecería, pues, la clave de su ilegitimidad en la nueva Europa.

En este artículo, sin embargo, vamos a transitar otro tipo de conceptualización acerca del término legitimidad, que se refiere específicamente al campo de la teoría política expuesta por Max Weber. Así, hablando en términos puramente weberianos, la legitimación del franquismo se podría corresponder con una heterogénea designación de elementos tradicionalistas y burocráticos. Para entender el cambio que sufre su estructura política -la que le lleva a adaptarse a ese nuevo orden mundial y, finalmente, a no desaparecer-hay que preguntarse, primero, quién manda políticamente en el centro de poder que es el franquismo. Y para contestar esta pregunta debe esclarecerse la situación de dominación que establece la legitimidad de un poder hacia sus ciudadanos. Es decir, ¿cuál es el sentido de legitimidad con el que el franquismo pretende establecer su poder y ejercer una dominación política?

En el tipo de dominación y obediencia hacia el poder (Macht), Weber (2016: 69) distinguió claramente entre Herrschaft y Autorität. El primero corresponde al modo en que la sociedad está en condiciones de aceptar el mando político en cuestión, de acuerdo a parámetros diversos pero siempre voluntariamente. El segundo consiste en el acatamiento al poder por la mera imposición, donde el poder del gobernante se detenta a través de la fuerza o coacción. Por eso aquí no se va a hablar de la dominación por represión directa (tema que ha sido ampliamente investigado dentro de la historia del franquismo) sino de cómo se da una legitimación positiva ante la sociedad y ante los demás Estados.

Es cierto que la legitimación que nunca pretendieron ocultar los franquistas fue la que les proveyó la victoria en la Guerra Civil. A la construcción contrarrevolucionaria, antimoderna y de extrema derecha que fue el resultado para España al final de la contienda se le debe añadir, además, la sacralización de la guerra como cruzada y la beatificación de los vencedores como santos y mártires. Por otro lado, por mucho que en el franquismo de primera hora existieran verdaderos burócratas en el seno de su gobierno - porque ciertamente 
los hubo ${ }^{6}$ - no se deduce de ello una dominación burocrática ni una dominación cercana a la legal o jurídica. De hecho, el personalismo de Franco hacía imposible una dirección cercana a las antes nombradas, cayendo en las variaciones tradicionalistas o caudillistas. El caudillismo y su teoría principal la sugirió insistentemente Francisco Javier Conde, quien condensa en el plano teórico el estadio jurídico-político del franquismo que representa las bases falangistas del Movimiento Nacional ${ }^{7}$. Y sin ser Franco una figura carismática al estilo de los viejos representantes fascistas, el mandato de caudillo como virtud providencialista otorgada por la Iglesia hacía de su figura el portador de prebendas autojustificativas.

Efectivamente, tendremos que esperar hasta las reformas gubernamentales del año 1957 para que este tipo de acciones políticas se vayan diluyendo ante formas de dominación amparadas en otros ideales, más ajustados a la "dominación racional" weberiana. Solo bajo la perspectiva institucionalista tras las reformas legislativas a partir de estos gobiernos se encuentra la clave de la burocratización real del Régimen. Siguiendo de cerca la senda de Weber, Manuel García-Pelayo acometió la explicación de aquella etapa evolutiva en la que regímenes basados en el carisma del líder tienden a crear estructuras que permiten manejar el complejo social. Es precisamente entonces cuando el aparato burocrático emerge para mantener en el tiempo una dominación carismática o tradicional, que de otra forma no podría sobrevivir (García-Pelayo 1982: 91). Por tanto, aun partiendo de posiciones puramente tradicionalistas y caudillistas, se va a lograr un estadio burocrático, completando así la necesaria institucionalización burocrática del carisma.

La Ley de Régimen Jurídico de la Administración del Estado de 1957 es un claro ejemplo de este cambio en el modo de entender la acción política, que finalmente se corresponde con una forma weberianamente racional de adoptar las decisiones políticas. Esta ley se inspira en un modelo de eficacia administrativa que coadyuva la desconcentración de competencias del mando único, al otorgar ciertas capacidades al recientemente creado Ministerio Subsecretario de la Presidencia. Los gobiernos sucesivos, amparados en su eficiencia técnica, marginarían a Franco de la dirección diaria del poder estatal ${ }^{8}$.

${ }^{6}$ Esta es la conclusión que se recoge en Dahlström, C. y Lapuente, V., Organizing Leviathan. Politicians, Bureaucrats and the Making of Good Government (Cambridge, 2017). Ver también el completo estudio de la burocracia española en: Bañón, R., Poder de la burocracia y Cortes franquistas, 1941-71 (Madrid, 1978).

${ }^{7}$ Ver el clásico estudio de este autor: F. J. Conde, Contribución a la doctrina del caudillaje (Madrid, 1942). Otros teóricos también representativos de esta doctrina son, por ejemplo, Luis Legaz Lacambra, Eugenio Vegas Latapié o Juan Beneyto.

${ }^{8}$ Si bien Franco se alejó de la toma de decisiones en ciertos ámbitos y de la forma perenne a la estaba acostumbrado, pudo fortalecer su figura política y social al atribuirse lo éxitos económicos que el nuevo rumbo gubernamental estaba imprimiendo. Ver: J. M. Zaratiegui, “¿Los mismos perros con distintos collares? Solución de continuidad entre la tercera fuerza y la tecnocracia española”, en Brocar, 43 (2019), p. 247.

Araucaria. Revista Iberoamericana de Filosofia, Política, Humanidades y Relaciones Internacionales, año $23, \mathrm{n}^{\circ} 47$. Segundo cuatrimestre de 2021. Pp. 233-253. ISSN 1575-6823 e-ISSN 2340-2199 https://dx.doi.org/10.12795/araucaria.2021.i47.11 
La otra cara de la moneda fue la cuestión sobre la legitimación del franquismo en el aspecto religioso. Como se apuntó al principio, en un momento epocal de guerra fría, de lucha contra el comunismo y de la presentación del franquismo como resguardo de la moral cristiana en su preciada localización estratégica, el breve resquicio que el autoritarismo franquista aceptaba para que la tradición social se mantuviera a expensas de algunos avances modernizadores fue clave. Pero los cambios conllevaban un desprendimiento de los más íntimos rasgos tradicionalistas del Régimen. Como diría más adelante José Casanova (1999: 144), "la tecnocracia, las ideologías del desarrollo y las que proclamaban el final de la ideología llegaron a sustituir al catolicismo como base para la legitimación ideológica del régimen", en unos tiempos de clara tendencia secularizadora.

Cabe descartar, por tanto, cualquier idea relacionada con la apertura social y la transigencia del franquismo durante estos "cambios", y mucho menos la otorgación de nuevas leyes y derechos reales. El Régimen ni siquiera se planteó adaptar su condición religiosa a los nuevos tiempos (especialmente tras el Concilio Vaticano II y las apuestas por un catolicismo más social y progresista) en pos de asumir unos postulados con los que contexto histórico le apremiaba. Hacerlo le hubiera supuesto perder esa pátina de legitimidad que, aun de forma no política, le ofrecía una condición positiva ante la sociedad.

Lo que sí se dio fue un tipo concreto de modernización en el franquismo, que debe entenderse específicamente como la progresiva burocratización de la estructura política interna, reforzando la vía administrativa para la dominación racional. El fin que perseguía esta reforma era la consecución de unas cotas de superávit económico que le permitieran presentarse como un país solvente y de cierta relevancia en el escenario internacional. La burocratización del Régimen llegó desde un camino fácilmente rastreable si atendemos a la variación de los contrapesos políticos internos, como se ha apuntado. Estos ajustes previos le permitieron ganar flexibilidad a la hora de adaptarse a las estructuras imperantes propias de la época.

\section{Una era de desideologización}

Antes de popularizarse el magnánimo "fin de la historia" lo había hecho otra corriente con cierta similitud en sus postulados, y que ya empezaba a intuir la época finalista en unas sociedades con claros imperativos posmodernos: el fin de las ideologías. El iniciador de esta corriente intelectual es otro controvertido autor estadounidense, que también recibió, junto a la polémica de su argumentación, la crítica abierta de los sectores de izquierda. Daniel Bell escribió en 1960 su obra más célebre con el nombre mismo de The End 
of Ideology. Sus tesis son suficientemente conocidas, y centran el tiro en el declive de las ideologías políticas como factores clave en la vida política, un declive que se habría de iniciar en Occidente ya desde los años 50, coincidiendo con el mundo bipolarizado de posguerra que contextualiza precisamente este artículo. Sin embargo, con el libro de Bell ocurre lo mismo que con el clásico de Fukuyama: se conocen vagamente las tesis, sus ideas generales se popularizan, pero en realidad no se ha solido leer detenidamente. De hecho, Bell decidió redactar un epílogo para futuras ediciones de su opúsculo a la altura de 1988, porque entendía que sus principales tesis habían sido interpretadas erróneamente.

La estructura principal del libro de Bell se enfoca en diseccionar la sociedad estadounidense en relación a su sistema político y a las vicisitudes que el capitalismo está experimentando, en la línea que Raymond Aron estaba estableciendo y a quien, por cierto, dedica ese epílogo. Es el fin de la ideología como retórica, como el motor incapaz de mover a la sociedad porque sus resortes están oxidados por las viejas disputas sin poder performativo alguno. La conclusión a la que conduce este diagnóstico es el declive de las fuerzas ideológicas tradicionales que estructuraban las sociedades industriales clásicas, dominadas por las deudas idealistas propias del siglo XIX. ¿Quiénes ocuparán la vacante dejada por las exhaustas ideas europeas? Bell lo tiene claro: las nuevas formas sociales e ideológicas de los países emergentes en proceso de industrialización, especialmente los asiáticos y los africanos. Este punto nos interesa especialmente, ya que para Bell los objetivos de las viejas ideologías eran "la igualdad social" $y$, en último término, "la libertad", mientras que el impulso de las nuevas ideologías proviene del desarrollo económico y del “empoderamiento nacional” (Bell 1988: 403).

Pues bien, varios autores han puesto sobre el papel, recalcando una vez más la poco novedosa idea central de Fukuyama, que la culminación de la Guerra Fría y el triunfo de la opción occidental es algo que bajo otros ropajes se venía dando en la "guerra de las ideologías"9. Tiene lógica si pensamos en que hay una argumentación compartida (agotamiento de las ideologías extremas, decadencia de las tendencias políticas clásicas, superación en una sola doctrina aparentemente neutra...) y, sobre todo, un discurso finalista común que tiende a proyectar una velada defensa del statu quo liberal.

Por otro lado, se ha señalado también a estos intelectuales afines al finalismo ideológico como los engendradores de la nueva tecnocracia política de los años 50 y 60, lo cual conectaría con las premisas teóricas que se adscriben a la postura económico-política de la España de esos años. El ya

\footnotetext{
${ }^{9}$ Fontana (1992: 11) advertirá que "tanto Bell como Marcuse ya habían dicho esto tres décadas antes”. También Ludivine Bantigny (2015: 19) asume que Fukuyama solo prolonga lo que Daniel Bell pensó que había visto en 1962: el supuesto fin de las ideologías.
}

Araucaria. Revista Iberoamericana de Filosofia, Politica, Humanidades y Relaciones Internacionales, año $23, \mathrm{n}^{\circ} 47$. Segundo cuatrimestre de 2021. Pp. 233-253. ISSN 1575-6823 e-ISSN 2340-2199 https://dx.doi.org/10.12795/araucaria.2021.i47.11 
mencionado Daniel Bell siempre rechazó la acusación generalizada que recibió de ser el adalid teórico de la tecnocracia, pero sus críticos le reprocharon que su doctrina antiideológica preparaba -consciente o involuntariamente- el camino hacia un tipo de estadio político en el que las clásicas disputas ideológicamente tendenciosas perdían sus capacidades, quedando el terreno abonado para la imposición de la nuda técnica.

Siguiendo esta corriente, ya en el caso español, se ha solido llamar adalid de la tecnocracia a Gonzalo Fernández de la Mora, algo que sin embargo requiere ulteriores puntualizaciones. En principio tiene sentido esa caracterización, visto el sospechoso título que establecía una relación directísima entre esos debates del fin de las ideologías, especialmente desde la obra cumbre de Bell. Y es que El Crepúsculo de las ideologías hacía referencia explícita a esos textos, por mucho que el futuro ministro español se preocupara de resaltar las diferencias entre ambas obras. Sin embargo, si hablamos de deuda intelectual o teórica más allá de esa equivalencia nominal, se puede afirmar que Fernández de la Mora obtuvo más influencia teórica del francés Jean Meynaud que de Bell, al menos en la consideración de sus escritos sobre las formas políticas que debía adoptar el franquismo. Meynaud (1964) sí teorizó específicamente sobre las ideologías en su relación con la tecnocracia, y se podría decir que de una manera más neutral ${ }^{10}$. Si bien su obra no ha alcanzado una repercusión similar a la de Bell o Fukuyama, sus textos sobre el supuesto agotamiento de las ideologías durante los años 50 y 60 fueron ampliamente conocidos. Las tesis de Meynaud se dieron a conocer al gran público concretamente a través de dos textos que pueden verse como complementarios: "El destino de las ideologías" y "Tecnocracia y política".

La obra del ideólogo español, en este sentido, se puede llegar a entender perfectamente sobre las coordenadas de dos importantes conceptos en la obra de Meynaud: opulencia y apaciguamiento. Sobre el primer concepto opera una idea clave para el periodo desarrollista del franquismo que, de nuevo, fue compartido por la gestión económica occidental: lograr unas cotas de desarrollo económico cuyo éxito permeara hacia la situación social de la población, incrementando la renta individual y avalando mejoras en las políticas de bienestar material, con el objetivo final de reducir las posibilidades revolucionarias de la ideología soviética. La explicación a esto no deja de ofrecerse en una cándida sencillez, que reside en el balance entre economía y demandas políticas. Por supuesto, el desarrollismo económico y sus efectos inmediatos en la mejora de la calidad de vida de los ciudadanos anularían también, siguiendo aquellas argumentaciones, las voces críticas que desde la política exigían más justicia social o el desarrollo

${ }^{10}$ En España, la introducción del pensamiento de Meynaud debió su popularidad a la compilación de ambos textos, editados por Jorge Esteban en 1964, bajo el célebre título "Problemas ideológicos del siglo XX".

Araucaria. Revista Iberoamericana de Filosofia, Política, Humanidades y Relaciones Internacionales, año $23, \mathrm{n}^{\circ} 47$. Segundo cuatrimestre de 2021. Pp. 233-253. ISSN 1575-6823 e-ISSN 2340-2199 https://dx.doi.org/10.12795/araucaria.2021.i47.11 
de otro tipo de derechos civiles. El aseguramiento de la "opulencia" material sería la panacea contemporánea de posguerra que evitaría, de este modo, el conflicto social nacional ante los sectores más progresistas. Esta fue una de las justificaciones usuales que el régimen franquista vociferó ante sus vecinos europeos y que a la vez le permitió ignorar de una manera "legítima" las voces de quienes demandaban una apertura política democrática (Ysàs y Molinero 2008).

Por el otro lado tenemos el concepto de "apaciguamiento", que sin duda se sincroniza perfectamente con el anterior. Este se encuentra todavía más presente si cabe en las obras de Fernández de la Mora, básicamente porque desarrolla, a partir de esa noción, toda una justificación política de por qué es erróneo buscar alternativas de democracia (real) para el organicismo franquista. La tesis principal adjunta a este concepto radica en la desaparición de las ideologías fuertes que imperaron durante los años 20 y 30 del siglo $\mathrm{XX}$ y que condujeron a climas insosteniblemente violentos. El problema era, precisamente, que estas ideologías (y sus derivaciones aisladas) fueron dictadas y conducidas por políticos demagogos que respaldaban su discurso en las emociones humanas ${ }^{11}$. El giro "apaciguador" consistiría en ahogar tales pasiones políticas en las aguas neutras de la eficacia política. Ahora bien, esta eficacia política solo asegura su existencia si encuentra un suelo abonado mediante la tranquilidad social generalizada y la ausencia de conflictos bélicos. Esto significará, irremediablemente, el establecimiento de un estadio de regularidad política y social, amparado en la continuidad de un discurso único legitimado, hegemónico, y en la inexistencia de voces discordantes válidas, cuyo objetivo primordial es claro: el defensa del statu quo.

Huelga decir que este discurso podía ser altamente aprovechable para el franquismo y su ferviente deseo de dominación sin sobresaltos y sin oposición de ningún tipo. El modo de equipararse a las corrientes de los países líderes fue la apelación a una supuesta desideologización cuyo principal propósito era dejar sin efecto las demandas democráticas, pues lo importante era el progreso técnico y económico, que quedaba por encima de la forma política. La legitimación final para el franquismo consistía en verse avalado por estos indicadores, no por las demandas de supuestos derechos humanos universales, lo cual concordaba con las virtudes de su democracia orgánica tradicional.

Fernández de la Mora recogió todo aquello que desde el discurso europeo podía servir a los intereses integristas del franquismo. Siguiendo sus célebres tesis crepusculares (Fernández de la Mora: 1965), la política se ha desplazado de la lucha ideológica a las formas cientificistas de entender el Estado y sus

${ }_{11}$ Patriotismo, racismo, supremacismo y nacionalismo extremo fueron algunas de estas tendencias en claro auge durante el periodo destacado, que por supuesto tienen su correlación existencial con el totalitarismo de las formas políticas. Ver: R. O. Paxton, The anatomy of fascism (London, 2005). 
cuestiones sociales. El integrismo católico sigue vigente para este tipo de pensadores, que tendieron a agruparse en centros intelectuales como Arbor o el mismo CSIC, y que compartían una meta institucionalizadora concreta, lejos de preceptos de otras familias franquistas. Sin embargo, la élite intelectual de esta corriente se desembarazará de las claves retóricas tradicionalistas para volcarse en esa modernización ya referenciada antes. Dicho brevemente: si se quería modernizar las estructuras burocráticas del Régimen, adscribirse a las corrientes intelectuales europeas - aunque fuera funcionalmente- y decretar la tecnocracia como modo velado de regir las opciones económicas del franquismo, resultaba imposible que el catolicismo subyugara la escena política. Fernández de la Mora (1965: 136) se encargó también de defender esta postura, aunque fuera otorgándole a la religión su posición central en otro tipo de aspectos sociales:

Aunque parcialmente irracionales, las religiones y las ideologías no se desarrollan paralelamente. El proceso de racionalización destruye las ideologías porque tienen una engañosa y frustrada pretensión social. Las creencias, en cambio, no solo son compatibles con la especulación pura, sino que han dado lugar a la filosofía; $y$, esencialmente, no corren con ello peligro alguno, porque en los pliegues más recónditos y radicales del dogma siempre hay núcleos irracionales inexpugnables por el logos.

La diferencia radicaría en la esencia social y políticamente formadora que tiene toda ideología, que aspira a regular las disposiciones de la vida pública. La religión, en cambio, si bien puede influir en las ideologías, no tiene como naturaleza esa aspiración social, pues se enmarcan en la pura relación humana con Dios sin que de ahí se deriven necesariamente preceptos morales o políticos.

Fuera de toda esta postura hegemónica hubo también grupos que, desde la oposición y normalmente en la clandestinidad, criticaron la visión unificadora de la historia que de algún modo legitimaba la existencia de la dictadura, lo cual no deja de presentarse como prueba de la fuerza de este relato finalista. El principal ariete que estas voces críticas utilizaron fue destapar la intencionalidad oculta en la retórica utilizada para sustentar estos discursos. La continua lucha por el desvelamiento de aquella impostura resaltaba precisamente la autojustificación del statu quo antes mencionado. El acometido crítico más potente provino de los círculos intelectuales que se agruparon en torno a la revista Cuadernos para el Diálogo. Por ejemplo, Raúl Morodo publicó en sus páginas un juicio certero acerca de lo que pretendía realmente Fernández de la Mora con sus escritos, atacándole por su "intencionalidad política y el contenido ideológico de su pretendida desideologización", ya que de este modo se producía una grave impostura al querer "trasladar los esquemas de los países supra-desarrollados a una situación, como la nuestra, de semidesarrollo, en otras palabras, desde el liberalismo anglosajón al integrismo y autoritarismo español" (Muñoz Soro 
2006: 127). Este es uno de los puntos que se desarrollan ampliamente en la reputada monografía de Javier Muñoz Soro sobre esta revista:

La cínica maniobra del franquismo al integrar la asepsia ideológica entre el resto de sus muy ideológicas fuentes de legitimidad resultaba evidente, pero semejante esquizofrenia política provocaba respuestas inevitablemente contradictorias de la oposición, por un lado, consciente de la necesidad de la política frente a la mera administración; por otro, de que la falta de vida política politiza todo en nuestro país ${ }^{12}$.

Se desprenden de este diagnóstico dos puntos clave: que la desideologización solo era la máscara que ocultaba los verdaderos vicios ideológicos del Régimen, y que este disfraz resultó ser realmente eficaz a la hora de desactivar la protesta política antifranquista. Todo ello sin que el nuevo panorama internacional le exigiera demandas democráticas, como ya habíamos visto que permitió Estados Unidos, por lo que toma más impulso, aún si cabe, la coartada de las políticas neutrales y asépticas - sin supuesta ideología- que reivindicara el superávit económico y no atendiera en absoluto los avances sociales. Lo importante era entonces la mejora financiera y la planificación estructurada, en un campo sembrado de acuerdos internacionales que afianzaran la máxima hegemonía posible del franquismo. Esta vía discursiva penetró en España de forma inapelable y justificó la modernización instrumental imitando en lo económico a los países democráticos más avanzados industrialmente.

\section{El ordoliberalismo en el franquismo}

Eric Hobsbawm, hablando de la "modernización económica, social, intelectual y administrativa" que los monarcas ilustrados habían asumido durante el siglo XVIII, establece una equivalencia explícita entre esa era pasada y la nuestra (o digamos, más acertadamente, la suya, porque el texto se publicó en el año 1962): la adquisición de los hábitos llamados "ilustrados" de aquellos absolutistas, nuevo adjetivo que sin duda conllevaba connotaciones positivas, encuentra una analogía contemporánea en el adjetivo "planificador" que a mediados del siglo XX subsumía gran parte de la política de Estado europea. Desde luego que se trataba de una nueva ola de economía política que llegó a dominar la esfera occidental, desde países como Francia, Alemania e

12 J. Muñoz Soro, Cuadernos para el diálogo (1963-1976). Una historia cultural del segundo franquismo, (Madrid, 2006), pp. 131-2. Curiosamente, los jóvenes seguidores de la filosofía reflejada en Cuadernos para el Diálogo seguían las máximas de Ruiz-Giménez al reclamar una vuelta de las pasiones políticas al tablero político dominado por los asépticos tecnócratas y su "dictadura del desarrollo" (Muñoz Soro 2006: 129). Ver también: G. Pasamar, “La influencia de 'Annales' en la historiografía española durante el franquismo: un esbozo de explicación” en Historia Social (2004).

Araucaria. Revista Iberoamericana de Filosofia, Política, Humanidades y Relaciones Internacionales, año $23, \mathrm{n}^{\circ} 47$. Segundo cuatrimestre de 2021. Pp. 233-253. ISSN 1575-6823 e-ISSN 2340-2199 https://dx.doi.org/10.12795/araucaria.2021.i47.11 
Italia $^{13}$, ya en su vuelta a la normalidad parlamentaria, llegando hasta los que menos remanentes democráticos y constitucionales tenían, como era la España de Franco. En efecto, no había necesidad de ningún programa estrictamente social, de acuerdo a los estándares típicos de la cultura democrática, para instaurar un sistema económico altamente racionalizado, tal y como hemos visto. Es así como esta costumbre planificadora se recubrió de un cierto mantra, bien asegurado por el creciente beneficio de los ingresos nacionales que otorgaba y, sobre todo, por su consolidación como ideología del progreso racional comunitario, del que se aprovecharon los políticos y jefes de Estado de toda índole. El mantra del ilustrismo en pasadas épocas funcionó también pero, para Hobsbawm, tanto hoy como entonces "muchos de los que lo adoptaron en teoría hicieron muy poco para llevarlo a la práctica, y algunos de los que lo hicieron, lo hicieron movidos por un interés en las ideas generales que para la sociedad suponían la 'ilustración' o la 'planificación', que por las ventajas prácticas que la adopción de tales métodos suponía para el aumento de sus ingresos, riqueza y poder" (Hobsbawm, 2011: 30).

Este es el último punto esencial para entender la supervivencia del Régimen a través de la conformación de un discurso legitimador eminentemente económico, que le permitió equipararse en cierto modo a las potencias occidentales que venían desarrollando este tipo de políticas. El modelo económico predominante durante los años 50 y 60 -al menos en gran parte de Europa y Estados Unidos- puede establecerse como una suerte de "capitalismo tardío" o de organización (Habermas, 1999: 68), y se establece como sustitución y a la vez complemento del mercado autónomo, dando fin al capitalismo liberal clásico tal y como se entendía hasta entonces.

La asunción del liberalismo de posguerra se importó también a España desde unos postulados capitalistas muy concretos, ligados a la planificación de la economía, a través del capitalismo ordoliberal. El ordoliberalismo nació en el círculo de la intelectualidad económica alemana conocido como la Escuela de Friburgo, y que ya antes de la guerra -concretamente, en pleno auge de los movimientos fascistas- preveían un necesario cambio en el modo de entender la relación entre Estado y economía. En torno a la revista Ordo auspiciaron un movimiento que a la postre originaría el nuevo liberalismo económico instalado en la también nueva República Federal Alemana (Martín Rodríguez 2016). Esa denominación de "orden" hace referencia a la específica relación entre las regulaciones constitucionalistas y estatales de la sociedad y la implantación

\footnotetext{
${ }^{13}$ Las políticas económicas de Ehard en Alemania (1948), Einaudi en Italia (1947) y Rueff en Francia (1958) serán, de hecho, los modelos económicos a seguir por los gobiernos desarrollistas del franquismo. Ver: M. Martín. La escuela de Friburgo y los economistas españoles, (Madrid, 2016), p. 46. Un libro reciente de Jesús Zaratiegui explica la importación a España de la doctrina tecnocrática directamente desde el modelo francés. Ver: J. Zaratiegui, La tecnocracia y su introducción en España (Valladolid, 2019).
} 
de una política económica adherida a esos valores. En él primará la libertad económica y el capitalismo industrial y de emprendimiento, pero en el horizonte siempre se mantendrá una meta de "libertad" arraigada en preceptos de la filosofía nacional. Fuera de dudas queda que la libertad concreta solo puede realizarse en la realidad social a través de ese sistema económico-político, y sin embargo la pieza central que asegura y a la vez regula la correcta aplicación de la economía liberal le corresponde al Estado constitucional y democrático. Así, aunque la piedra pivotante de la teoría ordoliberal es el mercado capitalista, la regulación de sus condiciones ha de provenir necesariamente de un actor institucional. Dicho de otro modo: el capitalismo debe quedar sometido a las leyes propias de la estructura jurídica, que le otorga precisamente ese "orden" que lo regula.

Por lo tanto, esta planificación no puede separarse de su correspondencia nominal que se condensa en la fórmula mannheimiana de "planificación para la libertad". Esta es la noción concreta de la economía surgida en Alemania tras la guerra, y encierra aquel sentido liberal que es su base misma. El objetivo, y esto hay que tenerlo claro, es aupar el sistema liberal-capitalista -amparado por el constitucionalismo y desde luego vinculado al mercado- a la posición dominante que ha perdido durante las etapas de totalitarismo político. Del mismo modo, tanto creadores como discípulos de estos principios de economía niegan las designaciones puras de "planificación" en el sentido de intervencionismo a la manera fascista o comunista. Lo que buscarán reiteradamente será conseguir una tercera vía entre el laissez-faire radical y la intervención completa del Estado. Es por ello que este sistema se contrapone al conocido neoliberalismo, o liberalismo de raíz austríaca, al menos en cuanto a la negación de las realidades naturales que para el neoliberalismo autorregulan los mecanismos sociales. Por el contrario, se hace necesaria la ordenación estatal desde la política misma, encargada de mediar entre los dos espacios.

¿Por qué podría interesar tanto al franquismo importar esta forma de entender la economía política? Más allá de verse obligado a solucionar asuntos concretos con los que lidiaba en esos momentos (grave crisis económica debido a la gestión autárquica llevada a cabo hasta entonces, apremio por ajustarse a parámetros de acuerdo a las normas financieras internacionales, etcétera), el franquismo podía servirse del ordoliberalismo en tanto herramienta válida para su eterno deseo de adaptación hacia el exterior. Una vez más, el franquismo encontró el recoveco doctrinal -escondido esta vez tras la idea foucaultiana de la legitimación del Estado por la economía- que permitiera justificar o incluso avalar su existencia ${ }^{14}$.

${ }^{14}$ Esta idea proviene de los análisis sobre la historia del neoliberalismo de los franceses Christian Laval y Pierre Dardot, principalmente desde su libro conjunto La nueva razón del mundo. Ensayo sobre la sociedad neoliberal (Barcelona, 2013). Ver también: L. Álvarez, "La economía otra y la invención del Neoliberalismo". 
Es fácil comprender que cualquier vía exitosa hacia tal liberalismo, teniendo en cuenta el carácter esencialmente antiliberal del régimen de Franco, no podía recaer en otra forma que no fuera un programa económico apoyado directamente en la planificación estatal de la esfera económica ${ }^{15}$, cuya ideología aportara ciertos matices compartidos por el franquismo. Ejemplos históricos de economía planificada y estatalmente dirigida habían sido los gobiernos totalitarios. El franquismo, en cambio, ignorará la crítica planteada por los defensores del ordoliberalismo en su intento de evitar este tipo de regímenes: no es la economía capitalista burguesa la que disuelve fatalmente los lazos sociales tradicionales, sino la asunción de poder estatal y su crecimiento altamente desarrollado con respecto a las demás esferas públicas y privadas. Es evidente que la dictadura no pudo ni quiso dejar de lado su naturaleza represiva. Pero también es cierto que se daban diferencias marcadas entre la sistematización política nazi, por ejemplo, y el tipo de régimen dictatorial que es el franquismo, lo que nos devuelve a las viejas discusiones sobre el estatuto autoritario/totalitario de la España de Franco que se popularizaron desde los años 70 con Juan José Linz y otros. Es por ello que, una vez más, no es del todo ajustable una definición de la planificación económica puramente fascista con el caso español.

Volviendo a nuestro tema, cabe preguntarse cómo conseguiría finalmente el ordoliberalismo producir una legitimación suficiente como para mantener una dictadura ultraderechista en una Europa de mayoría democrática. Esto no deja de tornarse complejo ante la hipotética transferencia de virtudes civiles que la economía produce a través del Estado, y que en teoría lo impregnan. Así, existe para este liberalismo una clara legitimación del Estado en tanto que este, aplicando el derecho público, organiza positivamente la economía y, a través de la libre disposición económica en la sociedad, produce una ansiada libertad positiva. El Estado, por lo tanto, quedaría legitimado al regular una economía que produce verdadera libertad civil (Laval y Dardot 2013: 106).

Para ulteriores investigaciones queda la cuestión de cómo se podría establecer, en el franquismo, un sistema puramente económico eliminando esa parte esencial sobre la supuesta virtud civil que se contrae en su aplicación, como parece que ocurrió. Desde luego que la explicación debe encontrarse cercana a la compleja noción de modernización mencionada anteriormente. Pero pasemos al punto concreto donde más puede confluir el franquismo político con el liberalismo económico descrito y la formación de legitimidad. Por su

\footnotetext{
15 "Aunque había nacido como una reacción liberal frente al nacionalsocialismo, sus principales representantes proponían una fuerte intervención del Estado, que se creía era una necesidad en la España de la postguerra, y, contrariamente a Keynes, que simpatizaba con el partido liberal británico, ellos lo hacían con partidos conservadores", M. Martín Rodríguez, La escuela de Friburgo y los economistas españoles (Madrid, 2016), p. 15. Aunque, con todo, esta adhesión "a la conservadora" no justificaría por sí misma la aceptación de postulados que pudieran contravenir los principios básicos del Régimen.
}

Araucaria. Revista Iberoamericana de Filosofia, Política, Humanidades y Relaciones Internacionales, año $23, \mathrm{n}^{\circ} 47$. Segundo cuatrimestre de 2021. Pp. 233-253. ISSN 1575-6823 e-ISSN 2340-2199 https://dx.doi.org/10.12795/araucaria.2021.i47.11 
misma raíz filosófica, el ordoliberalismo, y esto es lo fundamental, incide en un sentido de legitimación no solamente económico, sino sociológico, pues un Estado legítimo es "un Estado que se somete al derecho, que respeta el principio de libertad de elección, por supuesto, pero es también un Estado que obedece al principio de subsidiariedad, tal y como lo defiende la doctrina católica, o sea, que respeta los medios de integración de los individuos en las esferas naturales jerarquizadas" (Laval y Dardot 2013: 108). Así las cosas, eliminado ese molesto pasaje sobre el principio de libertad de elección y los derechos civiles, no hay nada que pudiera congratular más a la élite franquista que la reivindicación de las unidades naturales como la familia o el municipio, desde donde encuentra de hecho el fundamento que erige su celebrada "democracia orgánica". Esas "realidades sociales", con amplias reminiscencias cristianas, se convertirán para el franquismo en fundamentos autojustificativos donde encuentre finalmente una explicación racional y "europea” para legitimar sus esfuerzos antiparlamentarios.

La penetración en España de esta intelectualidad provino, como no podía ser de otra forma, de aquellos círculos compartidos por integristas -muchos de ellos adheridos al Opus Dei- que nutriría aquel grupo difuso de tecnócratas, aunque el Instituto de Estudios Políticos y otras instituciones de diversa condición ideológica también invitaron ocasionalmente a sus referentes. La continua visita de intelectuales ordoliberales invitados por los modernizadores integristas a la casa franquista es fácilmente rastreable: Stackelberg en 1943, Eucken en 1949, Röpke en 1950, etcétera (Martín Rodríguez, 2016). Además, jóvenes economistas españoles en formación viajaron hasta Alemania para formarse con ellos, y las traducciones de las principales obras del ordoliberalismo, de la mano de Rialp con un activo Rafael Calvo Serer ya a la cabeza, no se hicieron esperar.

Fue precisamente Calvo Serer quien se encargaría de entablar una conexión fecunda entre el economista Wilhelm Röpke y los postulados que perseguía el integrismo franquista con su idea de modernizar a España administrativa y económicamente. Si bien no se puede hablar propiamente de connivencia entre el economista alemán y el franquismo, sí se llegó a tal punto de alabar el sentido tradicional y cristiano que se había perdido bajo los totalitarismos y que seguía en peligro de desaparición debido ahora al influyente control soviético. De un modo similar a como haría Carl Schmitt, Röpke (1962) admite que en la centralidad de la civilización europea, reconocida como "seno materno" todavía digna de ejemplo, posee España una posición histórica valiosa y asimismo respetada como guardiana de la tradición europea católica. Más allá de las cuestiones espirituales, la visión estatalista de Röpke encontró también una fácil recepción en aquella España: si bien le niega al Estado la superioridad absoluta de todas las esferas, le adscribe por otro lado la capacidad 
de mantenerse independiente de grupos de interés económicos, lo que le convertiría en un Estado verdaderamente fuerte al servicio de los intereses de "su comunidad" (Molina 2001: 54).

Por otro lado, la tercera vía sobre la que teorizaría Röpke -marca de la casa del ordoliberalismo clásico- consistente en un camino intermedio entre la totalización estatal y el capitalismo clásico, encontró en Calvo Serer un altavoz privilegiado para el caso español y además repercutió en su movimiento sobre la tercera fuerza. Es claro que el valenciano conocía bien el trabajo del alemán. En un artículo publicado en La Vanguardia, a la altura de 1957, Calvo utilizó un escrito de Röpke para atacar a los "liberales del (neo)liberalismo", o sea, a aquellos que siguen la doctrina del neoliberalismo, que por supuesto queda bien diferenciada, para Calvo, del liberalismo que representa el alemán. Se trataba de nuevo de sacar a relucir los resortes antiliberales del franquismo, en el sentido de despreciar la primacía de la soberanía popular con la "volonté genérale", la aplicación rígida del principio de "laisser faire, laisser passer" y el desvanecimiento del individuo de las "sociedades primarias en las que naturalmente se desenvuelve"16. Y así como Röpke enalteció a esa España históricamente cristiana, Calvo Serer pudo denominarle, con un tono pretendidamente elogioso, como de "antiliberal".

El franquismo logró adaptar su peculiar ordoliberalismo para la política económica. El Régimen continuó cimentando su ideología ultranacionalista y alargando sus principios básicos reaccionarios, aunque adquiriera premisas de ese movimiento para su economía política, resumido aquí bajo la fórmula de "nacional-liberalismo". Solo así logró colocarse en el vagón de cola de los países liberales occidentales, lo que le permitió una supervivencia estable aunque por momentos agónica, y definitivamente legitimada ya por el discurso hegemónico liberal. Todas las aparentes paradojas relativas a la modernización franquista (¿no constituye un modo de presión, para la adopción de unas formas concretas político-sociales, el integrar un sistema económico que precisamente necesita de esa característica para llegar a su fin último [la libertad concreta]? ¿Fue tan fácil eliminar ese requisito de libertad e incluir todo el resto? ¿Tuvo influencia, mediante desgaste interno, para la disolución progresiva y final del franquismo?) adquieren un sentido específico cuando se plantean a la luz de la compleja situación historiográfica que sumerge a España -hasta casi ahogarlaen el panorama político internacional.

${ }^{16}$ R. Calvo Serer, "Los neoliberales ante la libertad", en La Vanguardia (17/01/1957). 


\section{Bibliografía:}

Álvarez, L. (2013). "La economía otra y la invención del Neoliberalismo”, en Araucaria. Revista Iberoamericana de Filosofia, Politica y Humanidades, 31. pp. 25-39.

Bantigny, L. (2015). “La fin de l'histoire n'aura pas lieu”, en Écrire l'histoire, 15, pp. $19-26$.

Bañón, R. (1978). Poder de la burocracia y Cortes franquistas (1941-71). Madrid: Instituto Nacional de Administración Pública.

Bell, D. (1988). The End of Ideology. New York: Harvard University Press.

Bueno G. (1992). "Estado e historia (en torno al artículo de Francis Fukuyama)", en El Basilisco. Revista de Materialismo Filosófico, 11.

Casanova, J. (1999). "España: de la Iglesia estatal a la separación de Iglesia y Estado", en Historia Social, 35, pp. 135-152.

Conde, F. J. (1942). Contribución a la doctrina del caudillaje. Madrid: Ediciones de la Vicesecretaría de Educación Popular.

Dahlström, C. y Lapuente, V. (2017). Organizing Leviathan. Politicians, Bureaucrats and the Making of Good Government. Cambridge: Cambridge University Press.

Paniagua, F. (1997). La ordenación del capitalismo avanzado en España: 1957-1963. Barcelona: Anagrama.

Fontana, J. (1992). La historia después del fin de la historia. Barcelona: Crítica.

Fukuyama F. (1992). El fin de la historia y el último hombre. Barcelona: Planet.

García-Pelayo, M. (1982). Burocracia y tecnocracia. Madrid: Alianza.

Habermas, J. (1999). Problemas de legitimación en el capitalismo tardio. Madrid: Cátedra. Hobsbawm, E. (2011). La era de la revolución. 1789-1848. Barcelona: Crítica.

Hobsbawm, E. (1994). Age of Extremes. The short twentieth century 1914-1991. London: Penguin Group.

Judt, T. (2012). Postguerra. Una historia de Europa desde 1945. Madrid: Taurus.

Laval, C. y Dardot, P. (2013). La nueva razón del mundo. Ensayo sobre la sociedad neoliberal. Barcelona: Gedisa.

Martín Rodríguez, M. (2016). La escuela de Friburgo y los economistas españoles. Madrid: Instituto Económico de Análisis Económico y Social.

Meynaud, J. (1964). Problemas ideológicos del siglo XX. Ariel: Barcelona.

Molina Cano, J. (2001). La tercera vía en Wilhelm Röpke. Navarra: Universidad de Navarra.

Muñoz Soro, J. (2006). Cuadernos para el diálogo (1963-1976). Una historia cultural del segundo franquismo. Madrid: Marcial Pons.

Nadal, J. (comp.) (1994). La economía española en el siglo XX. Una perspectiva histórica. Barcelona, Ariel.

Núñez Seixas X. (2015). Las utopías pendientes. Una breve historia del mundo desde 1945. Barcelona: Crítica.

Pasamar, G. (2004). "La influencia de 'Annales' en la historiografía española durante el franquismo: un esbozo de explicación”, en Historia Social, 48, pp. 149-172.

Paxton, R. O. (2005). The anatomy of fascism. London: Penguin Books.

Pinedo J. (2018). "Tres debates culturales durante la transición chilena a la democracia: el fin de la historia, el rol del intelectual, el Quinto Centenario", en J. Pinedo (coord.): Debates intelectuales, Santiago: Ariadna Ediciones. 
Röpke, W. (1962). “Europa desde fuera: Meditación sobre el ente y los límites de Europa”, en Arbor, 201, pp. 55-63.

Sánchez, M. (2020). Los ricos de Franco: Grandes magnates de la dictadura, altos financieros de la democracia. Barcelona: Roca Editorial.

Schmitt, C. (2009). Teología Política. Madrid: Trotta.

Tusell, J. (1993). Carrero. La eminencia gris del régimen de Franco. Madrid: Temas de hoy.

Viñas, Á. (1981). Los pactos secretos de Franco con Estados Unidos. Bases, ayuda económica, recortes de soberanía. Barcelona: Grijalbo.

Ryan, A. et al. (1992). A propósito del fin de la historia. Valencia: Debats.

Weber, M. (2016). Sociología del poder. Madrid: Alianza.

Ysàs, P. y Molinero, C. (2008). La anatomía del franquismo. De la supervivencia a la agonía, 1945-1977. Barcelona: Crítica.

Zaratiegui, J. M. (2019). “¿Los mismos perros con distintos collares? Solución de continuidad entre la tercera fuerza y la tecnocracia española” en Brocar, 43. 
